PROCESOS

ReVISTA ECUATORIANA de HISTORIA

\title{
Manifiesto para Quito II Congreso Internacional de Archivos "Nuevos modelos de gestión: retos y perspectivas" Reunión Internacional de Archiveros sin Fronteras
}

En la ciudad de Quito, a los 8 días del mes de junio del año 2018, los asistentes al II Congreso Internacional de Archivos "Nuevos modelos de gestión: retos y perspectivas" y a la Reunión internacional de Archiveros sin Fronteras, con la presencia de los delegados de Argentina, Brasil, Bolivia, Chile, Ecuador, España, México y Uruguay, luego de tres días de reflexión y debate sobre las temáticas planteadas durante los días 6,7 y 8 de junio de 2018, manifiestan lo siguiente:

1. Agradecer a la Universidad Andina Simón Bolívar, Sede Ecuador, a través del Área de Historia, y a Archiveros sin Fronteras, capítulo Ecuador, por la organización del II Congreso Internacional de Archivos;

2. Agradecer al Ministerio de Cultura y Patrimonio y al Consejo de la Judicatura del Ecuador por el auspicio de este evento;

3. Agradecer a los estudiantes del Programa de Maestría en Archivística y Sistemas de Gestión Documental por la organización y participación en la Casa Abierta;

4. Demandar a las entidades públicas y privadas el reconocimiento profesional a los archiveros para la realización de tareas inherentes a su formación;

5. Instar a las entidades responsables de repositorios documentales públicos y privados la planificación y asignación de recursos económicos para el adecuado desarrollo de los procesos técnicos documentales;

6. Requerir de las instituciones académicas y de la función pública la sostenibilidad de los programas de pregrado y posgrado universitarios en Archivística, así como de una formación continua y de cursos de capacita- 
ción para los funcionarios encargados y gestores de los repositorios documentales;

7. Exhortar a las instituciones públicas y privadas el acondicionamiento, renovación y modernización de la infraestructura de los acervos documentales;

8. Felicitar y respaldar a los profesionales y técnicos del Consejo de la Judicatura del Ecuador que han logrado una transformación de los archivos judiciales del país, y apoyar la continuidad de estos procesos para garantizar la estabilidad laboral de los profesionales en archivística;

9. Impulsar la actualización de la legislación nacional concerniente a los archivos; y,

10. Fomentar la generación de proyectos orientados a la investigación, procesamiento, conservación y difusión de los acervos documentales, con financiamiento público, privado y de cooperación internacional.

Quito, 8 de junio de 2018 Universidad Andina Simón Bolívar, Sede Ecuador 